\title{
Interrogating the Electrochemical Potential of Senna obtusifolia Mediated Biosynthesized Silver Nanoparticles
}

\author{
Solomon A. Mamuru*, Maxwell Happy \\ Electrochemical NanoLab, Department of Chemistry, Adamawa State University, P.M.B. 25, Mubi, Nigeria.
}

\section{A R T ICLE DETAILS}

\section{Article history:}

Received 05 June 2018

Accepted 27 June 2018

Available online 14 July 2018

\section{Keywords:}

Senna obtusifolia

Biosynthesis

Silver Nanoparticles

\begin{abstract}
A B S T R A C T
Hazards and toxicity associated with the physical and chemical synthesis protocol of metal nanoparticles has recently led researchers to seek alternative routes that is eco-friendly, cheap and fast; the green chemistry approach where plant extracts and microorganisms are used in the reduction of the metal salt is fast gaining popularity in the field of nanobiotechnology. However, controversy still trails acceptability; furthermore, electrochemical studies on these metal nanoparticles are limited. In this study, silver nitrate was reduced to its "nano silver form" through a one-step synthesis protocol using leaf extract of Senna obtusifolia. The usual microscopic and spectroscopic techniques such as UV-vis., FTIR, SEM, AFM and XRD were used to confirm the formation of silver nanoparticles. Electrochemical characterization using cyclic voltammetry and impedance spectroscopy further reveals the formation of silver nanoparticles via a redox process of $\mathrm{Ag}^{1+}$ to $\mathrm{Ag}^{0}$ with a formal potential value of $0.61 \mathrm{~V}$ vs. $\mathrm{Ag} \mid \mathrm{AgCl}$ $3 \mathrm{M} \mathrm{KCl}$.
\end{abstract}

\section{Introduction}

The extremely small size and large surface area of metal nanoparticles has currently attracted the attention for intense scientific research due to the significant differences in properties such as biological, catalytic activity, mechanical, melting point and optical absorption, thermal and electrical conductivity which are not observed in the same material at larger scale in their bulk form [1]. Because of these unique properties, metal nanoparticles are of particular interest for a number of applications ranging from catalysts, chemical sensors, electronic components, medical diagnostic imaging, pharmaceutical products, and medical treatment protocols. For example, metallic nanoparticles of noble metals such as gold, silver, platinum, and palladium have been widely used in products ranging from cosmetic to medical and pharmaceuticals [2, 3].

Although metal nanoparticles can be produced using a variety of traditional physical and chemical processes [4, 5], it is now possible to biologically synthesize materials via environment-friendly green chemistry based techniques [6]. Recently, nanotechnology and biology have converged into a new field known as nanobiotechnolgy where biological materials such as plants are used in a number of biochemical and biophysical processes. The biological synthesis via nanobiotechnology processes have significantly boosted nanoparticles production without the use of harsh, toxic, and expensive chemicals commonly used in conventional physical and chemical processes. This process involves the use of the plant phytochemicals which are usually responsible for the reduction of metal ion to its respective monovalent metal [7]. However, controversy still trails its acceptability due to stoichiometry. Furthermore electrochemical studies on biosynthesized metal nanoparticles is limited $[7,8]$. In this study, we investigate the formation of silver nanoparticles synthesized via Senna obtusifolia leaf extract using electrochemical techniques alongside microscopic and spectroscopic techniques.

\section{Experimental Methods}

\subsection{Materials}

Senna obtusifolia was obtained from the farmlands in Mubi metropolis. silver nitrate, sodium hydroxide pellets - BDH Chemical Ltd., England,
Jenway 6405 UV-visible spectrophotometer, Perkin Elmer Frontier Fourier transform infrared spectrophotometer (FTIR), Agilent 5500 atomic force microscopy (AFM) and Autolab PGSTAT 302N.

\subsection{Plant Extract Preparation}

Dried leaves of Senna obtusifolia were reduced into fine particles. $10 \mathrm{~g}$ of the pulverized leaves was weighed into a $250 \mathrm{~mL}$ conical flask. $50 \mathrm{~mL}$ of distilled water was added to the conical flask containing the leaves and boiled to around $80{ }^{\circ} \mathrm{C}-100{ }^{\circ} \mathrm{C}$ for $10 \mathrm{~min}$. The boiled leaves were then cooled and filtered with Whatman No. 1 filter paper to obtain the extracts.

\subsection{Synthesis of Silver Nanoparticles}

$200 \mathrm{~mL}$ stock solution of $0.01 \mathrm{M}$ silver nitrate was prepared. From the stock solution of $0.01 \mathrm{M}$ silver nitrate, $50 \mathrm{~mL}$ of it was placed in a $100 \mathrm{~mL}$ conical flask and $5 \mathrm{~mL}$ of Senna obtusifolia leaf extract was added drop wise with continuous stirring for 1 hour. A colour change was observed indicating the formation of silver nanoparticles $[9,10]$. The solution of silver nanoparticle formed was then centrifuge at $3000 \mathrm{rpm}$ for $10 \mathrm{~min}$ to obtain the deposit of silver nanoparticles which was then washed with ethanol and distilled water. The washed silver nanoparticle was allowed to air dry.

\subsection{Characterizations}

The sample was prepared for XRD analysis using a back loading preparation method. The PANalytical X'Pert Pro powder diffractometer was used for this analysis. The diffraction patterns were collected from $10^{\circ}$ to $90^{\circ}$ and phases identified using the X'Pert Highscore plus software. Surface morphology of the silver nanoparticles was obtained with a Agilent 5500 atomic force microscope employing the contact mode technique with a cantilever of resonant frequency $17 \mathrm{KHz}$ and spring constant of $0.08 \mathrm{~N} / \mathrm{m}$. Sheet of mica was used as substrate for placing the nanoparticles and Field emission scanning electron microscopy (FESEM) images were obtained from JEOL JSM 5800 LV (Japan) equipped with an energy dispersive X-ray spectroscopy (EDX). Digital processing of the SEM images was carried out using the UTHSCSA ImageTool software version 3.0 .

The solution chemistry of the silver nanoparticles was studied by UVvisible spectrophotometer at wavelength of 250-700 nm on a Jenway 6405 UV-visible spectrophotometer. The surface plasmon resonance SPR obtained from the study is presented in Fig. 1. 


\subsection{Electrochemical Characterization}

All electrochemical measurements were performed with an Autolab PGSTAT 302N driven by NOVA software version 1.9. The counter electrode was a platinum wire and an $\mathrm{Ag} \mid \mathrm{AgCl} 3 \mathrm{M} \mathrm{KCl}$ was used as the reference electrode.

\subsubsection{Electrode Preparation}

A platinum electrode $(3 \mathrm{~mm}$ diameter) was polished with alumina slurry (nano powder), and then cleansed with deionized water. $2 \mathrm{mg}$ of synthesized silver nanoparticles were dissolved in distilled water. $10 \mu \mathrm{L}$ of the silver nanoparticles solution was cast on the surface of the platinum electrode using a micropipette and allowed to dry at room temperature to prepare the platinum-silver nanoparticles electrode.

The electrochemical behaviour of the platinum-silver nanoparticles were studied with an outer sphere redox couple of $0.005 \mathrm{M}$ potassium ferricyanide and potassium ferrocyanide in $0.2 \mathrm{M} \mathrm{NaOH}$ solution using cyclic voltammetry and electrochemical impedance spectroscopy, EIS.

\section{Results and Discussion}

\subsection{UV-Visible Spectroscopy}

Silver nanoparticles are known to absorb light at wavelength ranging from 420-550 nm [11]. The UV-visible absorption spectrum presented in Fig. 1 shows a characteristic surface plasmon resonance (SPR) with absorbance at approximately $350-450 \mathrm{~nm}$ and peak maxima at $400 \mathrm{~nm}$, which can be attributed to the formation of silver nanoparticles; depending on the individual particle properties such as size and shape the exact position of SPR band may shift [12]. The shape of the plasmon band is almost symmetrical suggesting that the nanoparticle may not be evenly dispersed and uniform. The non uniformity of the silver nanoparticle leads to the broad absorption peak. The inset of Fig. 1 is the observed reaction colour when the clear solution of $\mathrm{AgNO}_{3}$ was exposed to the extract of Senna obtusifolia, obviously, there is a change in colour from the clear solution of $\mathrm{AgNO}_{3}$ to brown of the silver nanoparticles. Such change in reaction colour has been observed by other workers $[13,14]$.

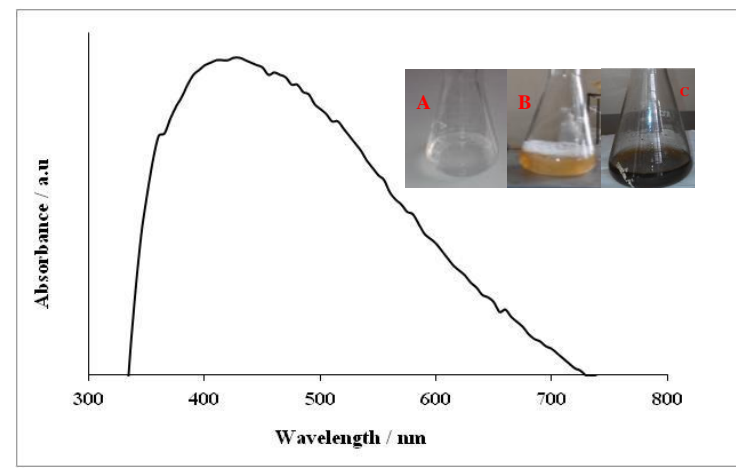

Fig. 1 UV-visible spectra of silver nanoparticles. (Inset) solution of silver nitrate (A), Senna obtusifolia (B) and silver nanoparticles (C)

\subsection{Atomic Force Microscopy (AFM)}

Fig. 2 shows the AFM topographical, deflection and cross sectional images of silver nanoparticles. The images reveal spherical shapes and non-aggregation of the nanoparticles, having average height of ca. $0.5 \mathrm{~nm}$. These shapes and arrangement is similar to most AFM images of silver nanoparticles synthesized using biological method $[15,16]$.

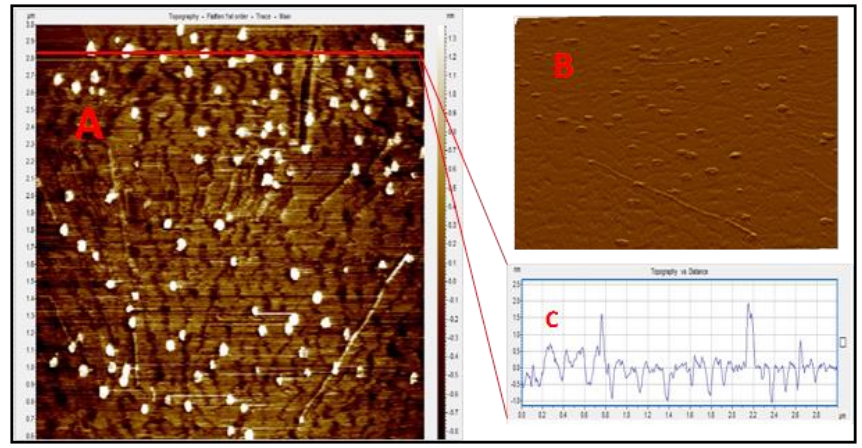

Fig. 2 AFM topographical image (A), deflection image (B) and cross sectional area (C) of silver nanoparticles

https://doi.org/10.30799/jnst.126.18040407

\subsection{Scanning Electron Microscopy (SEM)}

Fig. 3 shows the comparative SEM micrograph of $\mathrm{AgNO}_{3}$ and $\mathrm{Ag}$ nanoparticles. The images clearly indicate the transformation of the $\mathrm{AgNO}_{3}$ to nanoparticles of silver that are spherical in shape, nonaggregated and having an average diameter of $45 \mathrm{~nm}$.
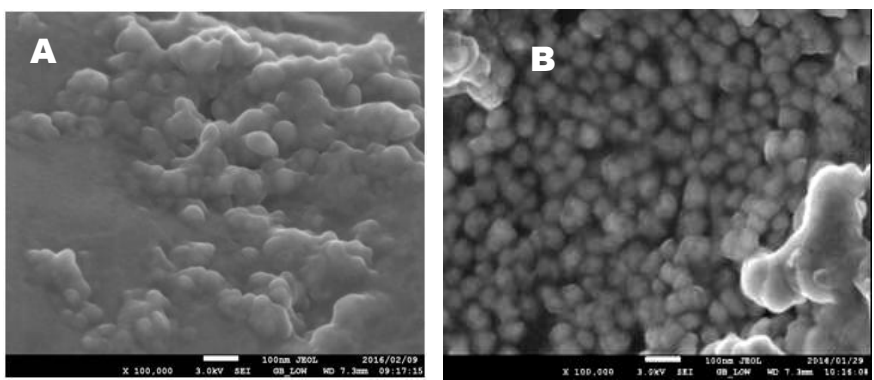

Fig. 3 SEM micrograph of $\mathrm{AgNO}_{3}(\mathrm{~A})$ and silver nanoparticles (B)

\subsection{Energy Dispersive Spectroscopy (EDS)}

$\mathrm{X}$-ray elemental microanalysis was obtained from a region observed by SEM from a drop of the resulting silver nanoparticle emulsion dried over a carbon surface. The most prominent peak obtained at the energy of $3 \mathrm{keV}$ corresponds to that of silver indicating the reduction of silver ions to element of silver. Other weak peaks for elements $\mathrm{C}, \mathrm{O}, \mathrm{N}$ and $\mathrm{Al}$ were also obtained. The inset quantitatively analysed the elements and measure them as $68 \% \mathrm{Ag}, 23 \% \mathrm{O}, 10 \% \mathrm{~N}, 4 \% \mathrm{C}$ and $0.28 \% \mathrm{Al}$.

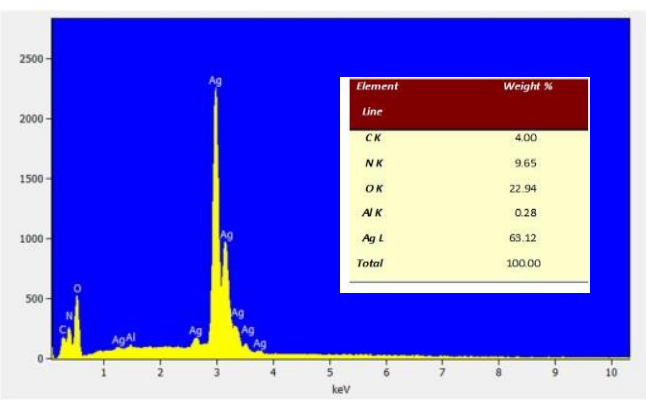

Fig. 4 Energy dispersive spectroscopy elemental analysis of Senna obtusifolia synthesized silver nanoparticles

\subsection{X-Ray Diffraction (XRD)}

The crystalline nature of the synthesized silver nanoparticles was further confirmed from their powder X-ray diffraction (XRD) patterns, as shown in Fig. 5. The presence of four lattice planes viz, (111), (200), (220), and (311) confirmed the formation of face-centered cubic (FCC) crystal structure of silver nanoparticles, and these lattice planes were associated with the diffraction peaks at ca $38.08^{\circ}, 44.04^{\circ}, 64.49^{\circ}$ and $77.34^{\circ}$. These results confirmed the formation of metallic silver, (JCPDS 04-0783) [17].

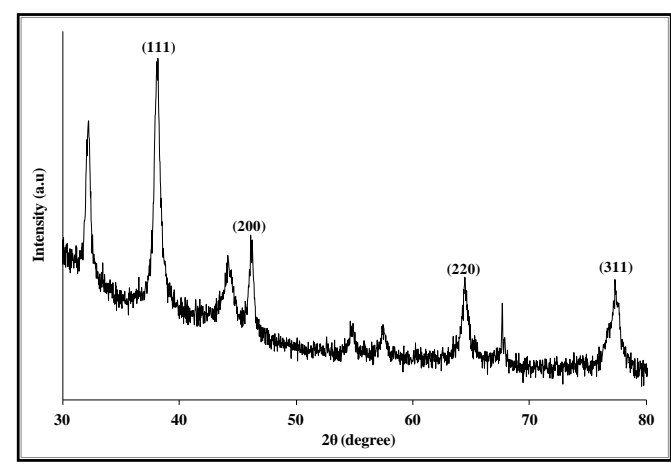

Fig. 5 XRD pattern of Senna obtusifolia synthesized silver nanoparticles

\subsection{FTIR Spectroscopy}

The Fourier transform infra-red spectroscopy analysis was performed to identify the possible biomolecule responsible for the bioreduction of $\mathrm{Ag}^{+}$ions and capping of the reduced silver nanoparticles synthesized using Senna obtusifolia. Fig. 6 shows the comparative spectra of Senna obtusifolia and silver nanoparticles. The result obtained for Senna obtusifolia leaves gave IR bands, at 3902, 3749, 3274, 2917, 2114, 1734, $1716,1699,1582,1556 \mathrm{~cm}^{-1}$. The IR bands for silver nanoparticles were observed at the following bands 3902, 3749, 2922, 2115, 1623, 1543, 
1523, 1501, 1456, $1379 \mathrm{~cm}^{-1}$. From the bands obtained for Senna obtusifolia leaves and silver nanoparticles, the bands at $1734 \mathrm{~cm}^{-1}$ and $1716 \mathrm{~cm}^{-1}$ are the ones in Senna obtusifolia leaves that are absent in silver nanoparticles. These bands are associated with $\alpha$-halo ketones and 1,2 diketones, syn-trans-open chains functional groups respectively [18]. Also, anthraquinone derivatives; flavonoids, tannins and saponins have been identified as one of the main phytochemicals component in Senna obtusifolia leaves [19]. Therefore, it can be suggested that the phytochemicals responsible for the reduction of $\mathrm{Ag}^{+}$to silver nanoparticles may be the group of ketones as anthraquinones.

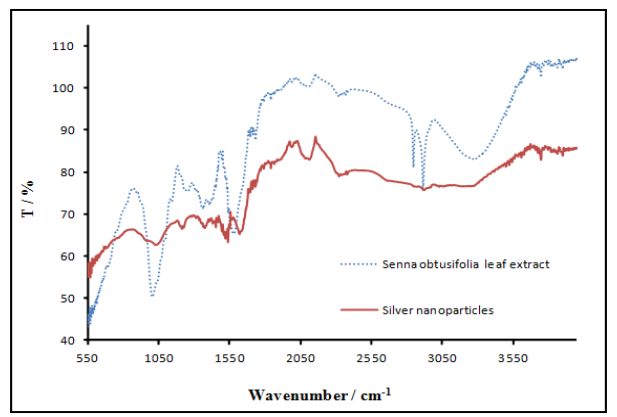

Fig. 6 FTIR spectra of Senna obtusifolia leaf extract (dashed line) and silver nanoparticles (solid line)

\subsection{Cyclic Voltammetric Characterization}

Figs. 7A and B show a comparison of the cyclic voltammetric behaviour of bare $\mathrm{Pt}$ and $\mathrm{Pt} / \mathrm{AgNP}$ respectively in solution of $0.005 \mathrm{M}\left[\mathrm{Fe}(\mathrm{CN})_{6}\right]^{3-/ 4-}$ containing $0.2 \mathrm{M} \mathrm{NaOH}$. The $\left[\mathrm{Fe}(\mathrm{CN})_{6}\right]^{3-} /{ }^{4-}$ solution is an important redox probe known to exhibit 1-electron reversible process. The choice of this redox probe in this research is to see at what extent can the AgNP specie permit the electron transfer of the $\left[\mathrm{Fe}(\mathrm{CN})_{6}\right]^{3-} /^{4-}$ species to the underlying Pt electrode in Fig. 7(A). The bare Pt electrode shows a pair of oxidation $\left(\mathrm{E}_{\mathrm{ox}}\right)$ and reduction $\left(\mathrm{E}_{\mathrm{red}}\right)$ peak potentials at $0.30 \mathrm{~V}$ and $0.17 \mathrm{~V}$ respectively. Analysis of the peak-to-peak separation gave a formal potential value at ca. $0.25 \mathrm{~V}$ which can be ascribed to $\mathrm{Fe}^{3+} / \mathrm{Fe}^{2+}$ redox process [20] while the Pt/AgNP modified electrode shows two pairs of oxidation and reduction peaks at $0.30 \mathrm{~V}$ and $0.17 \mathrm{~V}$ respectively, with a formal potential value at ca. $0.25 \mathrm{~V}$ which can also be ascribed to $\mathrm{Fe}^{3+} / \mathrm{Fe}^{2+}$ redox process, whereas the second pair of peaks occur at 0.68 and $0.54 \mathrm{~V}$ for the oxidation and reduction process respectively, which gave a formal potential value of 0.61 $\mathrm{V}$ and can be ascribe to $\mathrm{Ag}^{+} / \mathrm{Ag}^{0}$ redox process i.e.

$$
\mathrm{Ag}^{+}+\mathrm{e}^{-} \rightleftharpoons \mathrm{Ag}
$$

The formal potential of $0.61 \mathrm{~V}$ when converted is close to the standard electrode potential of $0.80 \mathrm{~V}$ vs. SHE for the Ag redox process [20], indicating that silver ion is reduced to silver metal: we must emphasize here that electrochemical studies of silver nanoparticles synthesized using plant extracts so far carried out by other workers; have not been able to establish the reversible reduction process of silver ion to silver metal [8, $15,21,22]$. In other words, this is the first time that a redox process showing the conversion of a biosynthesized silver nanoparticle from silver ion to silver nanoparticle is presented.
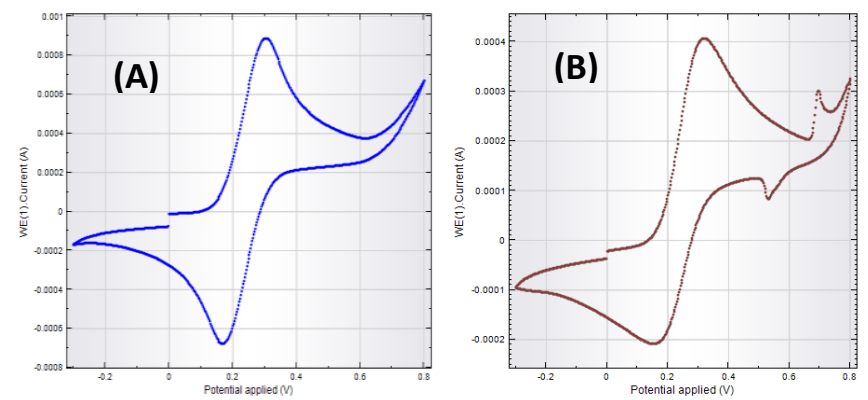

Fig. 7 Cyclic voltammogramms of Pt electrode (A), and Pt/AgNP electrode (B) in $0.005 \mathrm{M}\left[\mathrm{Fe}(\mathrm{CN})_{6}\right]^{3-/ 4-}$ in $0.2 \mathrm{M} \mathrm{NaOH}$ solution

\subsection{Electrochemical Impedance Spectroscopy}

The cyclic voltammetric study of modified species is only a fraction of an electrochemical system. Results of impedance measurements lead to a better explanation of the electrochemical system. Therefore, in this study on modified specie, we employed electrochemical impedance spectroscopy (EIS) to follow the charge-transfer kinetic, occurring at these electrodes surface. Impedance spectroscopy is a reliable non-destructive, informative technique for probing molecules or species at surfaces. It gives https://doi.org/10.30799/jnst.126.18040407 important information about processes at the electrode-electrolyte interface. Fig. 8 shows the Nyquist plots of Pt electrode (A) and Pt/AgNP electrode $(\mathrm{B})$ in $0.005 \mathrm{M}\left[\mathrm{Fe}(\mathrm{CN})_{6}\right]^{3-/ 4-}$ in $0.2 \mathrm{M} \mathrm{NaOH}$. Modified Randle equivalent electrical circuit $(C)$ was used to fit measurements obtained in Figs. 8(A) and (B).

The experimental data were fitted with the equivalent circuit involving double layer capacitance $\left(\mathrm{C}_{\mathrm{dl}}\right)$, constant phase element (CPE), solution resistance $\left(R_{s}\right)$ and charge-transfer resistance $\left(R_{c t}\right)$ representing the environment of the kinetic control. As seen in Fig. 8(A) and (B) the chosen equivalent circuit show satisfactory fittings (solid lines) with the experimental result (dotted lines). The impedance of the CPE $\left(\mathrm{Z}_{\mathrm{CPE}}\right)$ is given as:

$$
Z_{C P E}=\left[Q(j \omega)^{n}\right]^{-1}
$$

where $\mathrm{Q}$ is the frequency-independent constant related to the interface, $j=\sqrt{-1}, \omega$ is the radial frequency, the exponent $\mathrm{n}$ arises from the slope of $\log \mathrm{Z}$ vs. $\log \mathrm{f}$ (and has values $-1 \leq n \leq 1$ ). If $n=0$, the CPE behaves as a pure resistor; $n=1, C P E$ behaves as a pure capacitor; $n=-1, C P E$ behaves as an inductor; while $\mathrm{n}=0.5$ corresponds to Warburg impedance (W) which is associated with the domain of mass transport control arising from the diffusion of ions. In short, CPE arises from several factors such as (i) the nature of the electrode (e.g., roughness and polycrystallinity), (ii) distribution of the relaxation times due to heterogeneities existing at the electrode/electrolyte interface, (iii) porosity and (iv) dynamic disorder associated with diffusion [23].

The apparent electron transfer rate constant $\left(\mathrm{k}_{\mathrm{app}}\right)$ values of the electrodes were obtained using Eq.(2).

$$
k_{\text {app }}=\frac{R T}{n^{2} F^{2} R_{c t} C}
$$

where $\mathrm{n}$ is the number of electrons transferred, $\mathrm{C}$ is the concentration of the $\left[\mathrm{Fe}(\mathrm{CN})_{6}\right]^{-3}$ in mol cm${ }^{-3}$. The concentration of $\left[\mathrm{Fe}(\mathrm{CN})_{6}\right]^{3-} /\left[\mathrm{Fe}(\mathrm{CN})_{6}\right]^{4-}$ are equal. $\mathrm{R}$ is the ideal gas constant, $\mathrm{T}$ is the absolute temperature $(\mathrm{K})$ and $\mathrm{F}$ is the Faraday constant. The calculated values for the Pt electrode and $\mathrm{Pt} / \mathrm{AgNP}$ electrode are $7.27 \times 10^{-4} \mathrm{~cm} / \mathrm{s}$ and $5.32 \times 10^{-3} \mathrm{~cm} / \mathrm{s}$ respectively, indicating that the electron transfer processes between the redox probe and the underlying Pt surface are much easier at the Pt/AgNP electrode than the Pt electrode.
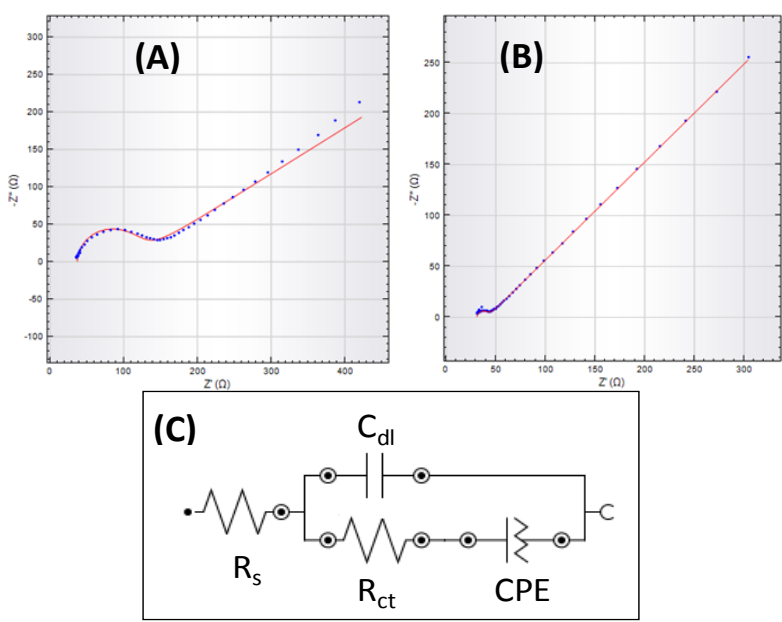

Fig. 8 Nyquist plots of Pt electrode (A), and Pt/AgNP electrode (B) in $0.005 \mathrm{M}$ $\left[\mathrm{Fe}(\mathrm{CN})_{6}\right]^{3-/ 4-}$ in $0.2 \mathrm{M} \mathrm{NaOH}$ solution. Dotted lines (measured), solid lines (fitted), Modified Randles equivalent electrical circuit (C) used to fit (A) and (B)

\subsection{Scan Rate Study Analysis}

The effect of scan rate on the peak current of Pt and Pt/AgNP modified electrode was examined with increases in scan rates from $100 \mathrm{mV} / \mathrm{s}$ to 800 $\mathrm{mV} / \mathrm{s}$ at interval of $100 \mathrm{mV} / \mathrm{s}$ for the bare electrode and 10 to $80 \mathrm{mV} / \mathrm{s}$ for $\mathrm{Pt} / \mathrm{AgNP}$ electrode. The oxidation and reduction peak current are linearly proportional to the square root of the scan rate which is expected for a diffusion controlled electrode process as shown in Figs. 9(B) and (C) and Figs. 10(B) and (C). At higher scan rates, the peak currents were proportional to the scan rate showing a surface confined redox process, which indicated the limitation arising from charge transfer kinetics. For higher scan rates, this theory predicts a linear dependence of $E_{p} v s . \log v$, which can be used to extract the kinetic parameters of $\alpha$ and Ks from the slope and intercept of such plots respectively. It is found that the $\Delta \mathrm{E}_{\mathrm{P}}$ values are proportional to the logarithm of the scan rate for higher scan rates. A plot of $\mathrm{E}_{\mathrm{p}} \mathrm{vs}$. $\log v$ yields two straight lines with slopes 2.3RT/(1$\alpha) \mathrm{nF}$ for anodic and $-2.3 \mathrm{RT} / \alpha \mathrm{nF}$ for the cathodic peak. 

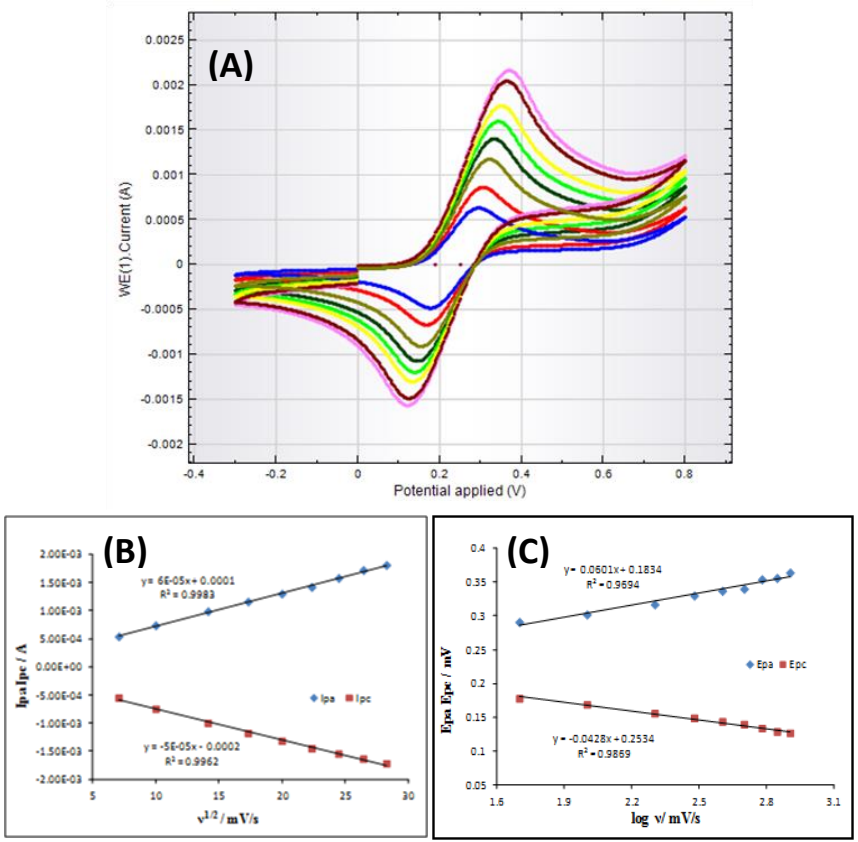

Fig. 9 Cyclic voltammograms of the Pt electrode at different scan rates in $0.005 \mathrm{M}$ $\left[\mathrm{Fe}(\mathrm{CN})_{6}\right]^{3-/ 4-} 0.2 \mathrm{M} \mathrm{NaOH}$ solution (A), scan rates from 100 to $800 \mathrm{mV} / \mathrm{s}$. Dependence of peak current $\left(\mathrm{Ip}_{\mathrm{a}}\right.$ and $\left.I \mathrm{I}_{\mathrm{c}}\right)$ versus square root of the scan rate $\left(\mathrm{v}^{1 / 2}\right)(\mathrm{B})$ and plot of the variation of peak potential versus logarithm of the scan rates $(\mathrm{C})$
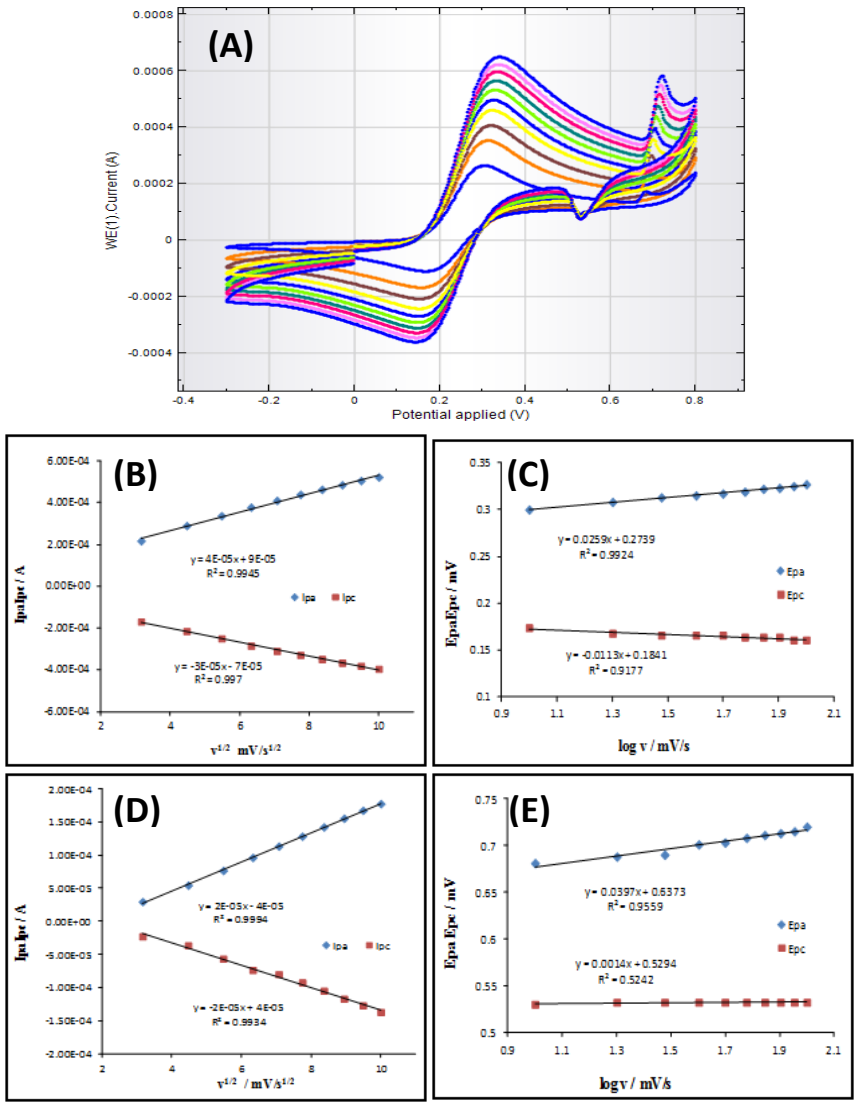

Fig. 10 Cyclic voltammograms of the Pt/AgNP electrode at different scan rates in $0.005 \mathrm{M}\left[\mathrm{Fe}(\mathrm{CN})_{6}\right]^{3-/ 4-} 0.2 \mathrm{M} \mathrm{NaOH}$ solution $(\mathrm{A})$, scan rates from 10 to $80 \mathrm{mV} / \mathrm{s}$. Dependence of peak current $\left(\mathrm{Ip}_{\mathrm{a}}\right.$ and $\left.\mathrm{Ip}_{\mathrm{c}}\right)$ versus square root of the scan rate $\left(v^{1 / 2}\right)$ (B) and plot of the variation of peak potential versus logarithm of the scan rates (C) for Pt and (D), (E) for AgNP

\section{Conclusion}

Silver ions were successfully converted to monovalent silver by reduction with leaf extract of Senna obtusifolia. Formation of the silver nanoparticles was confirmed by UV-visible spectroscopy, AFM, SEM, XRD and EDX, the particles are spherical in shape and non-aggregated with dimensions of ca. $45 \mathrm{~nm}$. FTIR spectroscopy reveals ketonic group as possible biomolecule responsible for the reduction. For the first time electrochemical technique was used to properly characterize biosynthesized silver nanoparticles, the result shows reversible peaks corresponding to reduction of $\mathrm{Ag}^{1+}$ to $\mathrm{Ag}^{0}$.

\section{Acknowledgement}

S.A.M will like to thank Adamawa State University for providing facilities and resources to carry out the work. M.H will like to thank Federal Polytechnic, Mubi for study fellowship.

\section{References}

[1] M. Daniel, D. Astruc, Gold nanoparticles: Assembly, supramolecular chemistry, quantum-size-related properties, and applications toward biology, catalysis, and nanotechnology, Chem. Rev. 104 (2004) 293-346.

[2] K. Saha, S.S. Agasti, C. Kim, X. Li, V.M. Rotello, Gold nanoparticles in chemical and biological sensing, Chem. Rev. 112(5) (2012) 2739-2779.

[3] L. Shang, T. Bian, D. Zhang, L.Z. Wu, C.H. Tung, Y. Yin, T. Zhang, Graphenesupported ultrafine metal nanoparticles encapsulated by mesoporous silica: robust catalysts for oxidation and reduction reactions, Angew. Chem. 53(1) (2014) 250-254.

[4] C. Hoppe, M. Lazarri, I. Pardinas-Blanco, M. Lopez-Quintela, One-step synthesis of gold and silver hydrosols using poly(N-vinyl-2-pyrrolidone) as reducing agent, Langmuir 22(16) (2006) 7027-7034.

[5] Y. Lu, Y. Mei, M. Schrinner, M. Ballauf, M. Moller, J. Breu, In situ formation of As nanoparticles in spherical polyacrylic acid brushes by UV-irradiation, J. Phys. Chem. C 111 (2007) 7676-7681.

[6] P. Yugandhar, T. Vasavi, P. Devi, N. Savithramma, Bioinspired green synthesis of copper oxide nanoparticles from Syzygium alternifolium (Wt.) Walp: characterization and evaluation of its synergistic antimicrobial and anticancer activity, Appl. Nanosci. 7 (2017) 417-427.

[7] S.A. Mamuru, N. Jaji, Voltammetric and impedimetric behaviour of phytosynthesized nickel nanoparticles, J. Nanostruct. Chem. 5 (2015) 347-356.

[8] A. Prabhu, K. Shankar, P. Muthukrishnan, A. Kathiresan, Electrochemical studies of biosynthesized silver nanoparticles by using Setaria verticillata plant, J. Adv. Chem. Sci. 2(3) (2016) 302-304.

[9] U. Gaware, V. Kamble, B. Ankamwar, Ecofriendly synthesis of anisotropic gold nanoparticles: A potential candidate of SERS studies, Int. J. Electrochem. 2012 (2012) 1-6.

[10] V.T.P. Vinod, P. Saravanan, B. Sreedhar, D. Keerthi Devi, R.B. Sashidhar, A facile synthesis and characterization of $\mathrm{Ag}, \mathrm{Au}$ and $\mathrm{Pt}$ nanoparticles using a natural hydrocolloid gum kondagogu (Cochlospermum gossypium), Colloids Surf. B 83 (2011) 291-298.

[11] Z. Khan, J.I. Hussain, A.A Hashmi, Shape-directing role of cetyltrimethyl ammonium bromide in the green synthesis of Ag-nanoparticles using Neem (Azadirachta indica) leaf extract, Colloid Surf. B 95 (2012) 229-234.

[12] R.S. Patil, M.R. Kokate, S.S. Kolekar, Bioinspired synthesis of highly stabilized silver nanoparticles using Ocimum tenuiflorum leaf extract and their antibacterial activity, Spectrochim. Acta A 91 (2012) 234-238.

[13] O.O. Oluwaniyi, H.I. Adegoke, E.T. Adesuji, A.B. Alabi, S.O. Bodede, A.H. Labulo C.O. Oseghale, Biosynthesis of silver nanoparticles using aqueous leaf extract of Thevetia peruviana Juss and its antimicrobial activities, Appl. Nanosci. 6(6) (2016) 903-912.

[14] B.D. Lade, A.S. Patil, Silver nano fabrication using leaf disc of Passiflora foetida Linn., Appl. Nanosci. 7(5) (2017) 181-192.

[15] K. Ponvel, T. Narayanaraja, T. Prabakaran, Biosynthesis of silver nanoparticles using root extract of the medicinal plant Justicia adhatoda: Characterisation, electrochemical behaviour and applications, Int. J. Nano Dimens. 6(4) (2015) 339-349.

[16] K. Satyavani, S. Gurudeeban, T. Ramanathan, T. Balasubramanian, Biomedical potential of silver nanoparticles synthesized from calli cells of Citrullus colocynthis (L.) Schrad, J. Nanobiotechnol. 9(43) (2011) 1-8.

[17] M.N. Alam, S. Das, S. Batuta, D. Mandal, N.A. Begum, Green-nanochemistry for safe environment: bio-friendly synthesis of fluorescent monometallic (Ag and $\mathrm{Au}$ ) and bimetallic ( $\mathrm{Ag} / \mathrm{Au}$ alloy) nanoparticles having pesticide sensing activity, J. Nanostruct. Chem. 6(4) (2016) 373-395.

[18] P. Patnaik, Dean's Analytical Chemistry Handbook, McGraw Hill, New York, 2004.

[19] I.Y. Sudi, D.M. Ksgbiya, E.K. Muluh, A. Clement, Nutritional and phytochemical screening of Senna obtusifolia indigenous to Mubi, Nigeria, Adv. Appl. Sci. Res. 2(3) (2011) 432-437.

[20] P. Vanysek, Electrochemical Series, In W.M. Haynes, Handbook of chemistry and physics, Chemical Rubber Company, Boca Raton, Florida, 2012. pp.5-80.

[21] L.B. Devi, A.B. Mandal, Self-assembly of Ag nanoparticles using hydroxypropyl cyclodextrin: synthesis, characterisation and application for catalytic reduction of p-nitrophenol, RSC Adv. 3 (2013) 5238-5253.

[22] Y. Li, S.M. Chen, A.M. Ali, F.M. AlHemaid, Biosynthesis and electrochemical characterization of silver nanoparticles from leaf extract of Adenium obesum and its application to antibacterial effect, Int. J. Electrochem. Sci. 8 (2013) 2691-2701.

[23] M. Orazem, B. Tribollet, Electrochemical impedance spectroscopy, Wiley, Hoboken, New Jersey, 2008. 